\title{
Determination of Fecal Shedding Rates and Genotypes of Swine Hepatitis E Virus (HEV) in Korea
}

\author{
Sung-Eun $\mathrm{KIM}^{1)}$, Mi-Young $\mathrm{KIM}^{1)}$, Do-Geun $\mathrm{KIM}^{1)}$, Young-Jo SONG ${ }^{1)}$, Hyun-Jeong JEONG ${ }^{1)}$, Sang-Won LEE ${ }^{1)}$, \\ Joong-Bok LEE ${ }^{1)}$, Seung-Yong PARK ${ }^{1)}$, Chang-Seon SONG ${ }^{1)}$, Soon-Jin $\mathrm{OH}^{2}$, Han-Sang YOO ${ }^{3)}$ and In-Soo CHOI ${ }^{1) *}$ \\ ${ }^{1)}$ Department of Infectious Diseases, College of Veterinary Medicine, Konkuk University, \#1 Hwayang-dong, Gwangjin-gu, Seoul 143-701, \\ ${ }^{2)}$ Department of Biomedical Science and Technology, Institute of Biomedical Science and Technology, Konkuk University, \#1 Hwayang- \\ dong, Gwangjin-gu, Seoul 143-701 and ${ }^{3)}$ Department of Infectious Diseases, College of Veterinary Medicine, Seoul National University, \\ San 56-1, Shillim-dong, Gwanak-gu, Seoul 151-742, Korea
}

(Received 1 May 2008/Accepted 2 August 2008)

ABSTRACT. Hepatitis E virus (HEV) infection induces an acute hepatitis or a subclinical disease in humans. It is known that HEV is a zoonotic agent and pigs are major reservoirs of HEV. This study was conducted to determine the fecal shedding rates of HEV in various age groups of pigs and identify the genotypes of swine HEV prevailing in Korea. A total of 565 fecal samples were collected from suckling piglets, post-weaning pigs, growing pigs, and sows at 12 swine farms. RT-PCR was used to detect the presence of swine HEV in the feces. Every swine farm examined in this study had HEV-infected pigs. The fecal shedding rates of the swine HEV at individual farms were in the range of $2.1-35.4 \%$. The overall fecal shedding rate of HEV in individual pigs was $17.5 \%$. The HEV shedding rates of suckling piglets, post-weaning pigs, growing pigs and sows in their feces were $6.3,16.3,38.0$ and 9.3\%, respectively. When the genotypes of swine HEVs identified in this study were determined, they were all grouped into genotype 3 . They were further subdivided into subtype 3a together with human and swine HEVs isolated in the U.S.A.

KEY WORDS: fecal shedding rate, genotype, hepatitis E virus, swine.

Hepatitis E virus (HEV) is usually a major causative agent of epidemic hepatitis in developing countries. However, sporadic hepatitis cases caused by HEV infections have been reported recently in industrialized countries [5, 15, 19]. HEV belongs to the genus Hepevirus in the family Hepeviridae and has a 7.2-kb positive-sense single-stranded RNA genome [17]. The HEV genome has three open reading frames (ORFs). The ORF1, ORF2, and ORF3 encode nonstructural proteins including an RNA-dependent RNA polymerase (RdRp), a capsid protein, and a small protein that possibly induces immune suppression in HEV-infected patients, respectively $[20,21]$. HEVs can be classified into 4 genotypes based on the phylogenetic analysis of the viral genomes. The Burmese, Mexican, American, and Chinese HEV strains are the prototype of genotypes 1, 2, 3, and 4, respectively $[6,18,19,23]$. Genotype $1 \mathrm{HEV}$ was isolated from several countries in Asia and Africa, genotype 2 was from Mexico, Nigeria, and Chad, genotype 3 was from a lot of countries in America, Asia, Europe, and Oceania, and genotype 4 was exclusively from Asian countries [10].

Since the prototype of swine HEV was isolated in the USA, lots of HEV strains have been isolated from pigs worldwide $[4,12,14,16,22]$. It was also revealed that considerably large populations of pigs were already infected with swine HEV. Seroprevalence studies indicated that about $15-70 \%$ of pigs were infected with HEV in several countries $[3,4,12,25]$. The infection rate of pigs measured

\footnotetext{
* Correspondence to: Choi, I. S., Department of Infectious Diseases, College of Veterinary Medicine, Konkuk University, \#1 Hwayang-dong, Gwangjin-gu, Seoul 143-701, Korea. e-mail: ischoi@konkuk.ac.kr
}

by detecting HEV RNA in the fecal specimens showed approximately $40 \%$ of pigs in the U.S.A. were infected by HEV [7]. A few studies were conducted in Korea to determine HEV infection rates with swine sera or liver tissues [4, 8]. However, there was no study to detect HEVs in swine feces and determine the genotypes and subtypes of the isolated HEVs in Korea. Therefore, we determined the fecal shedding rates of $\mathrm{HEV}$ in various age groups of pigs by detecting the viral RNA. Age-specific HEV infection status was identified within the pig populations. In addition, the phylogenetic analysis revealed that swine HEVs isolated in this study were all grouped into subtype 3a in genotype 3 .

A total of 565 fecal samples were obtained from 12 swine farms that were located in central and southern parts of Korea. The pig population of the farms was in a range of 1,000-3,000. In each farm, about 10-12 fresh fecal samples that had fallen on the floor of each breeding pen of suckling piglets (1 to 4 weeks), post-weaning pigs (5 to 10 weeks), growing pigs (11 to 24 weeks), and sows (more than 1 year of age) were collected. They were transported on ice to the Laboratory of Infectious Diseases, College of Veterinary Medicine, Konkuk University, Korea. One gram of feces resuspended in $12 \mathrm{~m} l$ of PBS was centrifuged at $1,200 \times \mathrm{g}$ for $30 \mathrm{~min}$. The supernatant was taken and centrifuged once more at $16,000 \times \mathrm{g}$ for $10 \mathrm{~min}$. The resulting supernatant was stored at $-70^{\circ} \mathrm{C}$ prior to analysis. Viral RNA was extracted from $200 \mu l$ of fecal solution with Accuprep Viral RNA Extraction kit (Bioneer, Korea) according to the manufacturer's instructions. Viral RNA was eluted in $50 \mu \mathrm{l}$ of elution buffer.

Two sets of primers were used for detection of a portion 
Table 1. Determination of the fecal shedding rate of HEV from different ages of pigs

\begin{tabular}{clclll}
\hline \multirow{2}{*}{ Swine farms } & \multicolumn{5}{c}{ No. of HEV-positive pigs at different ages } \\
\cline { 2 - 6 } & Suckling (\%) & $\begin{array}{c}\text { Post- } \\
\text { weaning (\%) }\end{array}$ & Growing (\%) & Sow (\%) & Total (\%) \\
\hline DW & $0 / 12(0.0)$ & $1 / 12(8.3)$ & $0 / 12(0.0)$ & $0 / 12(0.0)$ & $1 / 48(2.1)$ \\
DG & $1 / 12(8.3)$ & $0 / 12(0.0)$ & $11 / 12(91.7)$ & $2 / 12(16.7)$ & $14 / 48(29.2)$ \\
GS & $0 / 12(0.0)$ & $5 / 12(41.7)$ & $1 / 12(8.3)$ & $3 / 12(25.0)$ & $9 / 48(18.8)$ \\
HH & $0 / 12(0.0)$ & $1 / 12(8.3)$ & $5 / 12(41.7)$ & $0 / 10(0.0)$ & $6 / 46(13.0)$ \\
SS & $0 / 12(0.0)$ & $0 / 12(0.0)$ & $4 / 12(33.3)$ & $0 / 12(0.0)$ & $4 / 48(8.3)$ \\
JJ & $1 / 10(10.0)$ & $7 / 11(63.6)$ & $0 / 10(0.0)$ & $0 / 10(0.0)$ & $8 / 41(19.5)$ \\
GN & $3 / 12(25.0)$ & $2 / 10(20.0)$ & $2 / 12(16.7)$ & $2 / 12(16.7)$ & $9 / 46(19.6)$ \\
PJ & $0 / 12(0.0)$ & $5 / 12(41.7)$ & $0 / 12(0.0)$ & $0 / 12(0.0)$ & $5 / 48(10.4)$ \\
DJ & $1 / 12(8.3)$ & $0 / 12(0.0)$ & $2 / 12(16.7)$ & $2 / 12(16.7)$ & $5 / 48(10.4)$ \\
DK & $0 / 12(0.0)$ & $0 / 12(0.0)$ & $6 / 12(50.0)$ & $4 / 12(33.3)$ & $10 / 48(20.8)$ \\
KN & $3 / 12(25.0)$ & $2 / 12(16.7)$ & $12 / 12(100)$ & $0 / 12(0.0)$ & $17 / 48(35.4)$ \\
YS & $0 / 12(0.0)$ & $0 / 12(0.0)$ & $11 / 12(91.7)$ & $0 / 12(0.0)$ & $11 / 48(22.9)$ \\
Total & $9 / 142(6.3)$ & $23 / 141(16.3)$ & $54 / 142(38.0)$ & $13 / 140(9.3)$ & $99 / 565(17.5)$ \\
\hline
\end{tabular}

of the RdRp gene of HEV via nested RT-PCR, as reported previously [27]. The external and internal primer sets were designed to produce 383-bp and 352-bp of PCR products, respectively. The nucleotide sequences of the primer sets were as follows: external forward primer, 5'-CAT GGT AAA GTG GGT CAG GGT AT-3' (4,213-4,235); external reverse primer, 5'-AGG GTG CCG GGC TCG CCG GA-3' (4,576-4,595); internal forward primer, 5'-GTA TTT CGG CCT GGA GTA AGA C-3' (4,232-4,253); internal reverse primer, 5'-TCA CCG GAG TGY TTC TTC CAG AA-3' (4,561-4,583). All nucleotide positions in the primers referred to the Burmese HEV strain (Bur82, M73218). cDNA was synthesized in a total volume of $20 \mu l$, including $10 \mu l$ of the extracted RNA, $1 \mu l$ of external reverse primer (20 pmoles $/ \mu l$ ), $4 \mu l$ of $5 \mathrm{X}$ first strand buffer (Invitrogen), 2 $\mu l$ of $0.1 \mathrm{M} \mathrm{DTT}, 1 \mu l$ of $10 \mathrm{mM}$ dNTPs, $1.5 \mu l$ of RNase free water, and $0.5 \mu l$ of M-MLV Reverse Transcriptase (RT) (200 Units/ $\mu l$, Invitrogen). The reaction was incubated for $90 \mathrm{~min}$ at $37^{\circ} \mathrm{C}$ for the synthesis of cDNA, for 10 $\min$ at $70^{\circ} \mathrm{C}$ for inactivation of RT, and then for $5 \mathrm{~min}$ at $4^{\circ} \mathrm{C}$ for chilling. The synthesized cDNA was stored at $-20^{\circ} \mathrm{C}$. The first-round PCR was conducted in a total volume of 50 $\mu l$ including $5 \mu l$ of $10 \mathrm{X}$ PCR buffer containing $15 \mathrm{mM}$ $\mathrm{MgCl}_{2}$ (Fermentas), $1 \mu l$ of $10 \mathrm{mM}$ dNTPs mixture, $1 \mu l$ of external forward primer $(20$ pmoles $/ \mu l), 1 \mu l$ of external reverse primer $(20$ pmoles $/ \mu l), 0.5 \mu l$ of Super-Therm Taq polymerase ( 5 Units $/ \mu l$, Fermentas), $4 \mu l$ of cDNA, and 37.5 $\mu l$ of distilled water. The PCR conditions were composed of 40 cycles of denaturation for $30 \mathrm{sec}$ at $94^{\circ} \mathrm{C}$, annealing for $30 \mathrm{sec}$ at $61^{\circ} \mathrm{C}$, and extension for $30 \mathrm{sec}$ at $72^{\circ} \mathrm{C}$, and a final single extension for $10 \mathrm{~min}$ at $72^{\circ} \mathrm{C}$. The second, nested PCR was also conducted in a total volume of $50 \mu l$, including $2 \mu l$ of the first PCR product, $5 \mu l$ of $10 \times$ PCR buffer with $15 \mathrm{mM} \mathrm{MgCl} 2,1 \mu l$ of $10 \mathrm{mM}$ dNTPs mix, $1 \mu l$ of internal forward primer $(20$ pmoles $/ \mu l), 1 \mu l$ of internal reverse primer $(20$ pmoles $/ \mu l), 0.5 \mu l$ of Super-Therm Taq polymerase, and $39.5 \mu l$ of distilled water. The PCR was conducted for 35 cycles under the same conditions as describe for the first-round PCR.

Twenty-three samples of the nested-PCR products were cloned into the T\&A cloning vector (RBC Bioscience) according to the manufacturer's instructions. Plasmid DNAs containing the partial swine HEV RdRp gene were identified by automatic DNA sequencing (Macrogen, Korea). Eighteen swine HEV RdRp gene sequences were deposited to GenBank and assigned accession numbers (EU407806-EU407823). The genotyping of swine HEV isolated in this study was determined by construction of a phylogenetic tree via bootstrap analysis (1,000 repeats) with $28 \mathrm{HEV}$ nucleotide sequences isolated from humans, pigs, and deer using the MEGA program (MEGA v4.0).

The presence of HEV RdRp-specific RNA in the swine feces was detected as a 352-bp PCR product (data not shown). It had been shown previously that the partial RdRp gene amplified by the primer sets used in this study could substitute for the entire genome of HEV during the construction and analysis of the phylogenetic tree [27]. Therefore, we used the primer sets for the detection and analysis of HEV RNAs. HEVs were detected from all 12 swine farms examined in this study. The fecal shedding rate of $\mathrm{HEV}$ in each swine farm was in the range of $2.1-35.4 \%$ (Table 1). The overall HEV fecal shedding rate of pigs at the 12 swine farms was $17.5 \%$. The viral shedding rates of suckling piglets, post-weaning pigs, growing pigs, and sows were $6.3,16.3,38.0$, and 9.3\%, respectively (Table 1 ).

The nucleotide sequences of 18 swine HEVs determined in this study were analyzed along with those of $28 \mathrm{HEV}$ strains isolated from humans, pigs, and deer to determine their genotypes. All swine HEVs detected in this study were classified into genotype 3 which includes HEVs isolated from human, pigs, and deer in the U.S.A., Japan, and Kyrgyzstan (Fig. 1). The genotype $3 \mathrm{HEVs}$ were recently further classified into 10 subtypes [10]. Swine HEVs identified in this study were grouped into subtype 3 a with the U.S.A. human and swine HEV prototypes, such as US1, US2, and swUS1 (Fig. 1). They were separated from subtype $3 \mathrm{~b}$ 


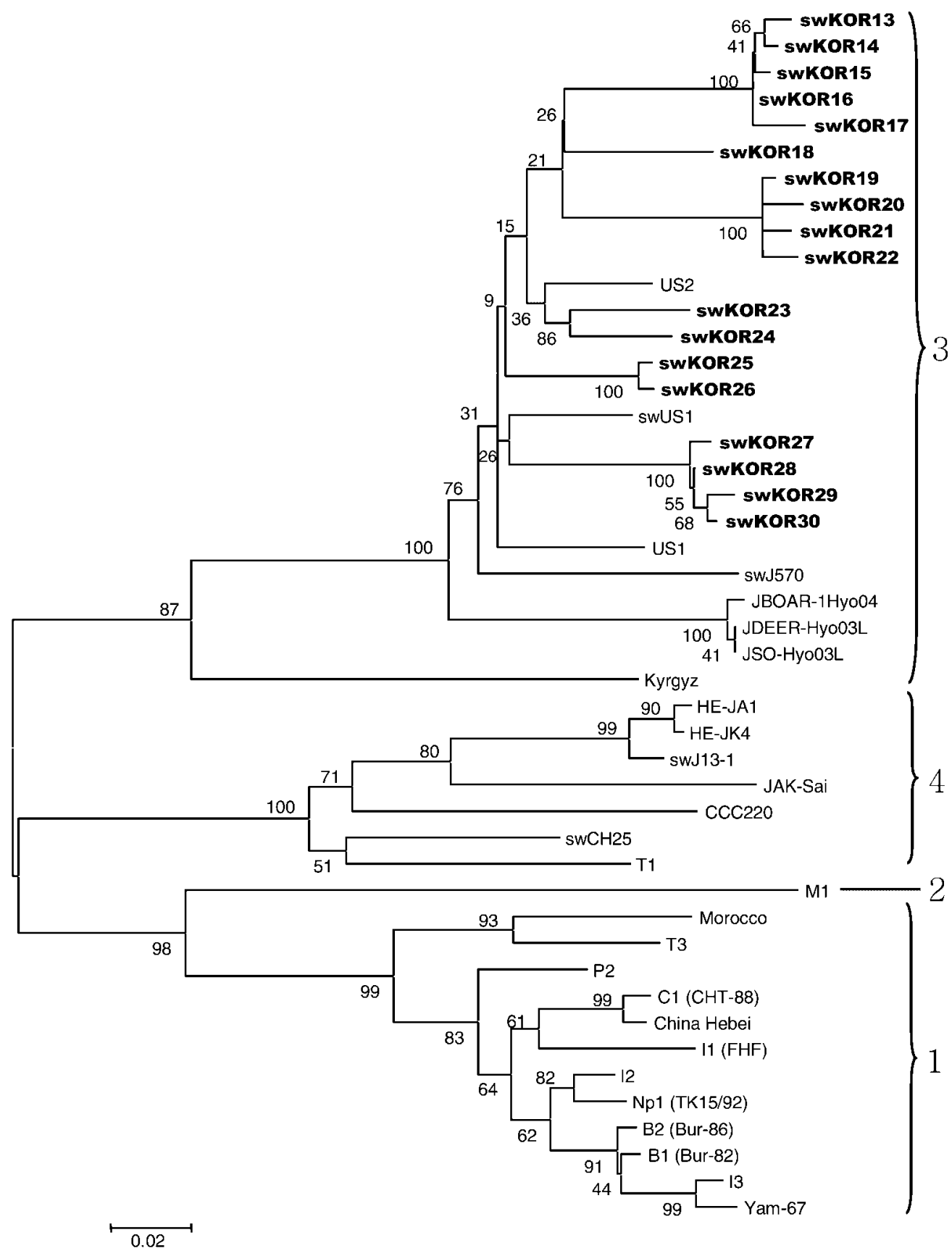

Fig. 1. Genotyping of swine HEV isolates by phylogenetic analysis. The analysis was performed with 307-bp of the partial RdRp gene amplified by RT-PCR. The scale bar represents nucleotide substitution per base. Bootstrap values indicate the percent of 1,000 replicates. Bold-faced letters represent the newly identified swine HEVs. The HEV isolates swKOR 13 and 23, 14, 15 and 17, 16, 18, 19 and 21, 20 and 22, 24, 25 and 26, 27 and 28, 29, and 30 were isolated from farms DG, SS, HH, GS, DW, GN, JJ, YS, PJ, DJ, DK, and KN, respectively. The GenBank accession numbers of HEVs used in this study for the construction of the phylogenetic tree were as follows; swKOR13 (EU407806), swKOR14 (EU407807), swKOR15 (EU407808), swKOR16 (EU407809), swKOR17 (EU407810), swKOR18 (EU407811), swKOR19 (EU407812), swKOR20 (EU407813), swKOR21 (EU407814), swKOR22 (EU407815), swKOR23 (EU407816), swKOR24 (EU407817), swKOR25 (EU407818), swKOR26 (EU407819), swKOR27 (EU407820), swKOR28 (EU407821), swKOR29 (EU407822), swKOR30 (EU407823), B1 (Bur-82) (M73218), B2 (Bur-86) (D10330), I2 (Mad-93) (X99441), Np1 (TK15/92) (AF051830), P2 (Abb-2B) (AF185822), Yam-67 (AF459438), I3 (AF076239), C1 (CHT-88) (D11092), China Hebei (M94177), I1 (FHF) (X98292), Moroco (AY230202), T3 (AY204877), M1 (M74506), swUS1 (AF082843), US1 (AF060668), US2 (AF060669), JBOAR-Hyo04 (AB189070), JDEER-Hyo03L (AB189071), JSO-Hyo03L (AB189073), swJ570 (AB073912), Kyrgyz (AF455784), HE-JA1 (AB097812), HE-JK4 (AB099347), swJ13-1 (AB097811), JAK-Sai (AB074915), swCH25 (AY594199), T1 (AJ271208), and CCC220 (AB108537). 
HEVs which include Japanese strains isolated from human (JSO-Hyo03L), pig (swJ570), boar (JBOAR-1Hyo04), and deer (JDEER-Hyo03L) on the phylogenetic tree.

The percent nucleotide identities of the partial RdRp gene of swine HEVs isolated in this study were compared with swine and human HEVs isolated from the U.S.A. and Japan (data not shown). The nucleotide sequences compared each other among the swine HEVs detected in this study showed $87.3-99.7 \%$ identity. When their nucleotide sequences were compared with those of human HEV prototypes, US1 and US2, they showed 89.6-94.8\% identity. In addition, swine HEVs isolated in this study demonstrated 90.6-93.2 and 87.0-90.6\% nucleotide identity with American swine HEV (swUS1) and Japanese swine HEV (swJ570), respectively. The comparison of deduced amino acid sequences of the partial RdRp gene demonstrated that swine HEVs examined in this study had 96.1-100 and 95.1-99.0\% identity with those American HEVs isolated from humans and pigs and with the Japanese swine HEV, respectively. These data indicated a closer genetic relationship between swine HEVs isolated in Korea and swine and human HEVs isolated in the U.S.A.

This study demonstrated the widespread HEV infections in the swine populations of Korea. The overall infection rates of swine HEV determined in a previous serological study [4] and in this study with feces were similar showing $15 \%$ and $17.5 \%$, respectively. Both post-weaning and growing pigs were shown to be more susceptible than other age groups to HEV infections. This observation confirmed that substantial HEV infection was likely initiated during the post-weaning period [26]. In this study, we examined 12 swine farms located in the central and southern parts of Korea and swine HEVs were detected from all of them. These findings suggested that the HEV infections were already prevailing at swine farms located in these regions. Other serological studies conducted in several countries similarly indicated a serious HEV infection status in pigs [1, $3,9,25]$.

Swine HEVs have highly related nucleic acid and amino acid sequences when compared to those of human HEVs [2, $12,15,24]$. It was experimentally demonstrated that swine HEV could infect nonhuman primates, such as rhesus monkeys and chimpanzees [11]. In addition to these observations, the occurrence of hepatitis patients who ate uncooked or under-cooked pig livers or intestines strongly suggested that swine HEVs are acting as zoonotic agents [13]. These observations raise a serious concern of transmission of swine HEVs to humans. In conclusion, we identified that considerably high populations of swine in Korea were infected with genotype $3 \mathrm{a}$ HEVs. They showed closely related genetic features with HEVs isolated from humans and pigs in the U.S.A.

ACKNOWLEDGMENT. This study was supported by a grant from the National Veterinary Research Quarantine Service (Z-AD14-2007-08-02).

\section{REFERENCES}

1. Arankalle, V. A., Joshi, M. V., Kulkarni, A. M., Gandhe, S. S., Chobe, L. P., Rautmare, S. S., Mishra, A. C. and Padbidri, V. S. 2001. Prevalence of anti-hepatitis E virus antibodies in different Indian animal species. J. Viral. Hepat. 8: 223-227.

2. Banks, M., Bendall, R., Grierson, S., Heath, G., Mitchell, J. and Dalton, H. 2004. Human and porcine hepatitis E virus strains, United Kingdom. Emerg. Infect. Dis. 10: 953-955.

3. Chandler, J. D., Riddell, M. A., Li, F., Love, R. J. and Anderson, D. A. 1999. Serological evidence for swine hepatitis E virus infection in Australian pig herd. Vet. Microbiol. 68: 95105.

4. Choi, I. S., Kwon, H. J., Shin, N. R. and Yoo, H. S. 2003. Identification of swine hepatitis E virus (HEV) and prevalence of anti-HEV antibodies in swine and human populations in Korea. J. Clin. Microbiol. 41: 3602-3608.

5. Clemente-Casares, P., Pina, S., Buti, M., Jardi, R., Martin, M., Bofill-Mas, S. and Girones, R. 2003. Hepatitis E virus epidemiology in industrialized countries. Emerg. Infect. Dis. 9: 448 454.

6. Huang, C. C., Nguyen, D., Fernandez, J., Yun, K. Y., Fry, K. E., Bradley, D. W., Tam, A. W. and Reyes, G. R. 1992. Molecular cloning and sequencing of the Mexico isolate of hepatitis E virus (HEV). Virology 191: 550-558.

7. Huang, F. F., Haqshenas, G., Guenette, D. K., Halbur, P. G., Schommer, S. K., Pierson, F. W., Toth, T. E. and Meng, X. J. 2002. Detection by reverse transcription-PCR and genetic characterization of field isolates of swine hepatitis $\mathrm{E}$ virus from pigs in different geographic regions of the United States. $J$. Clin. Microbiol. 40: 1326-1332.

8. Jung, K., Kang, B. Song, D. S. and Chae, C. 2007. Prevalence and genotyping of hepatitis $\mathrm{E}$ virus in swine population in Korea between 1995 and 2004: A retrospective study. Vet. J. 173: 683-687.

9. Lorenzo, F. R., Tsatsralt-Od, B., Ganbat, S., Takahashi, M. and Okamoto, H. 2007. Analysis of the full-length genome of hepatitis E virus isolates obtained from farm pigs in Mongolia. $J$. Med. Virol. 79: 1128-1137.

10. Lu, L., Li, C. and Hagedorn, C. H. 2006. Phylogenetic analysis of global hepatitis E virus sequences: genetic diversity, subtypes and zoonosis. Rev. Med. Virol. 16: 5-36.

11. Meng, X. J., Halbur, P. G., Shapiro, M. S., Govindarajan, S., Bruna, J. D., Mushahwar, I. K., Purcell, R. H. and Emerson, S. U. 1998. Genetic and experimental evidence for cross-species infection by swine hepatitis E virus. J. Virol. 72: 9714-9721.

12. Meng, X. J., Purcell, R. H., Halbur, P. G., Lehman, J. R., Webb, D. M., Tsareva, T. S., Haynes, J. S., Thacker, B. J. and Emerson, S. U. 1997. A novel virus in swine is closely related to the human hepatitis E virus. Proc. Natl. Acad. Sci. U.S.A. 94: 9860-9865.

13. Mizuo, H., Yazaki, Y., Sugawara, K., Tsuda, F., Takahashi, M., Nishizawa, T. and Okamoto, H. 2005. Possible risk factors for the transmission of hepatitis $\mathrm{E}$ virus and for the severe form of hepatitis E acquired locally in Hokkaido, Japan. J. Med. Virol. 76: 341-349.

14. Munné, M. S., Vladimirsky, S., Otegui, L., Castro, R., Brajterman, L., Soto, S., Guarnera, E., Molina, V., Monfellano, M., Schlauder, G. G. and González, J. E. 2006. Identification of the first strain of swine hepatitis E virus in South America and prevalence of anti-HEV antibodies in swine in Argentina. $J$. Med. Virol. 78: 1579-1583.

15. Nishizawa, T., Takahashi, M., Mizuo, H., Miyajima, H., 
Gotanda, Y. and Okamoto, H. 2003. Characterization of Japanese swine and human hepatitis E virus isolates of genotype IV with $99 \%$ identity over the entire genome. J. Gen. Virol. 84: 1245-1251.

16. Okamoto, H., Takahashi, M., Nishizawa, T., Fukai, K., Muramatsu, U. and Yoshikawa, A. 2001. Analysis of the complete genome of indigenous swine hepatitis E virus isolated in Japan. Biochem. Biophys. Res. Commun. 289: 929-936.

17. Panda, S. K., Thakral, D. and Rehman, S. 2007. Hepatitis E virus. Rev. Med. Virol. 17: 151-180.

18. Reyes, G. R., Purdy, M. A., Kim, J. P., Luk, K. C., Young, L. M., Fry, K. E. and Bradley, D. W. 1990. Isolation of a cDNA from the virus responsible for enterically transmitted non-A, non-B hepatitis. Science 247: 1335-1339.

19. Schlauder, G. G., Dawson, G. J., Erker, J. C., Kwo, P. Y., Knigge, M. F., Smalley, D. L., Rosenblatt, J. E., Desai, S. M. and Mushahwar, I. K. 1998. The sequence and phylogenetic analysis of a novel hepatitis $\mathrm{E}$ virus isolated from a patient with acute hepatitis reported in the United States. J. Gen. Virol. 79: 447-456.

20. Tam, A. W., Smith, M. M., Guerra M. E., Huang, C. C., Bradley, D. W., Fry, K. E. and Reyes, G. R. 1991. Hepatitis E virus (HEV): molecular cloning and sequencing of the full-length viral genome. Virology 185: 120-131.

21. Tyagi, S., Surjit, M. and Lal, S. K. 2005. The 41-amino-acid Cterminal region of the hepatitis $\mathrm{E}$ virus ORF3 protein interacts with bikunin, a Kunitz-type serine protease inhibitor. J. Virol. 79: $12081-12087$.
22. van der Poel, W. H. M., Verschoor, F., van der Heide, R., Herrera, M. I., Vivo, A., Kooreman, M. and de Roda Husman, A. M. 2001. Hepatitis E virus sequences in swine related to sequences in humans, the Netherlands. Emerg. Infect. Dis. 7: 970-976.

23. Wang, Y., Ling, R., Erker, J. C., Zhang, H., Li, H., Desai, S., Mushahwar, I. K. and Harrison, T. J. 1999. A divergent genotype of hepatitis E virus in Chinese patients with acute hepatitis. J. Gen. Virol. 80: 169-177.

24. Wibawa, I. D. N., Suryadarma, I. G. A., Mulyanto, Tsuda, F., Matsumoto, Y., Ninomiya, M., Takahashi, M. and Okamoto, H. 2007. Identification of genotype 4 hepatitis E virus strains from a patient with acute hepatitis $\mathrm{E}$ and farm pigs in Bali, Indonesia. J. Med. Virol. 79: 1138-1146.

25. Yoo, D., Willson, P., Pei, Y., Heyes, M. A., Deckert, A., Dewey, C. E., Friendship, R. M., Yoon, Y., Gottschalk, M., Yason, C. and Giulivi, A. 2001. Prevalence of hepatitis E virus antibodies in Canadian swine herds and identification of a novel variant of swine hepatitis E virus. Clin. Diagn. Lab. Immunol. 8: 1213-1219.

26. Yu, J. N., Kim, M. Y., Kim, D. G., Kim, S. E., Lee, J. B., Park, S. Y., Song, C. S., Shin, H. C., Seo, K. H. and Choi, I. S. 2008. Prevalence of hepatitis $\mathrm{E}$ virus and sapovirus in post-weaning pigs and identification of their genetic diversity. Arch. Virol. 153: 739-742.

27. Zhai, L., Dai, X. and Meng, J. 2006. Hepatitis E virus genotyping based on full-length genome and partial genomic regions. Virus Res. 120: 57-69 